\title{
Varsien poiston ja nostoajan vaikutus Realta-perunan satoon ja mekaanisten vikojen runsauteen
}

\author{
EERO VARIS \\ Hankkijan kasvinjalostuslaitos, Anttilan koetila, Hyrylä
}

Saapunut 8.1.1974

\section{The effects of haulm cutting and harvest time on the yield and on the amount of mechanical damage in Realta potatoes}

\author{
EERO VARIS \\ Hankkija Plant Breeding Institute, Experimental Farm Anttila, Hyrylä, Finland
}

\begin{abstract}
The study was carried out at the Plant Breeding Institute of Hankkija, Anttila Experimental Farm, from 1969-1971. Haulms were cut on August 20, the potatoes were harvested on September 07, 16, and 25. Determination of mechanical damage was done after a storage period of two months.

Haulm cutting decreased tuber yield by 11 per cent. Harvest time had no significant effect even though annual differences were found.

Haulm cutting and harvest time had no significant effect on the starch content. Yearly variations, however, were significant. Haulm cutting decreased the starch yield. The effect of harvest time on the starch yield varied yearly, but the average effect was insignificant.

Haulm cutting decreased the amount of large tubers and increased that of medium sized and small tubers. Harvest time had no effect in this respect.

Haulm cutting decreased the average tuber weight. There was no difference, however, at the latest harvest. Harvest time had no effect on tuber weight.

Haulm cutting reduced skin damage to an increasing degree at the last two harvests. Skinned tubers occurred least at the second harvest.

Haulm cutting decreased the amount of cuts and bruises at all harvests. The amount of cuts and bruises was lowest at the latest harvest.

Haulm cutting did not affect the occurrence of black spot. At the latest harvest, however, black spot occurred to a greater degree when the haulms had been cut.
\end{abstract}

Perunan tuotannon koneellistuttua ja viljelyn voimaperäistyttyä 1950-luvulta lähtien on erääksi pahimmista viljelyteknillisistä pulmista muodostunut perunoiden mekaaninen vioittuminen noston ja sitä seuraavan käsittelyn aikana (Nylund ym. 1955, Glemmestad 1957, Lampe 1960, Lööw 
1964, SEPPÄNEN 1972 a). Ratkaisuja tähän pulmaan on haettu toisaalta koneiden ja laitteiden laatua ja käyttötapaa tarkistamalla (esim. SPEchr 1967), toisaalta selvittämällä perunan mukuloiden vioittumisherkkyyteen liittyviä tekijöitä (Dambroth 1967, Rantanen ja Varis 2969, Hunnius ja Fuchs 1970, Fuchs 1971, SEPPÄNEN 1972 b). Tämän tutkimuksen tarkoituksena oli lähinnä selvittää, missä määrin varsien mekaaninen poisto ja nostoaika yhdessä vaikuttavat perunoiden käsittelynkestävyyteen. Samalla seurattiin eräitä muita sekä sadon määrään että laatuun liittyviä tekijöitä.

\section{Koeaineisto ja sen käsittely}

Tutkimus tehtiin Hankkijan kasvinjalostuslaitoksen Anttilan koetilalla vuosina 1969-71 (3 vuotta). Koejärjestely oli seuraava:

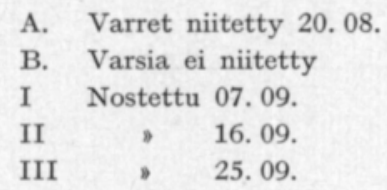

Ruudut olivat 2-rivisiä, $7.5 \mathrm{~m}$ pitkiä, ja niissä oli 50 mukulaa ruutua kohti. Kerranteita oli 4. Lajike oli Realta. Koealue oli maalajiltaan aitosavipohjaista multamaata. Lannoituksena käytettiin $1000-1300 \mathrm{~kg} / \mathrm{ha} \mathrm{Yklv}$, joka mullattiin rivimultaimella ennen istutusta istutusvakojen poikkisuuntaan.

Varret poistettiin niittämällä ja perunat korjattiin normaaliin tapaan säkkiin nostavalla "Nosto-Juko»-perunannostokoneella. Sadot lajiteltiin »Juko»tasoseulalajittimella ja varastoitiin sen jälkeen kellariin laatikoissa n. 2 kk:n ajaksi kolhiintumisanalyysejä varten.

Seuraavat ominaisuudet tutkittiin:

1. Mukulasato. Sadot (tn/ha) punnittiin lajittelujen yhteydessä.

2. Tärkkelyspitoisuus. Joka ruudusta otettiin $5 \mathrm{~kg}: \mathrm{n}$ tärkkelysnäyte. Mukuloiden paino $+18^{\circ} \mathrm{C}$ vedessä määritettiin Mettler K 7-sähkővaa'alla. Tärkkelyspitoisuuden määräämisessä käytettiin Hals \& Buchholz'in taulukkoa.

3. Tärkkelyssato. Edellisten tietojen perusteella laskettiin tärkkelyssadot (tn/ha).

4. Kokojakautuma. Ruutusadot lajiteltiin kolmeen kokoon: alle $40 \mathrm{~mm}, 40-55 \mathrm{~mm}$ ja yli $55 \mathrm{~mm}$. Tulokset on esitetty \%:ina koko sadosta.

5. Mukuloiden keskipaino. Tärkkelysnäytteistä määritettiin mukuloiden keskimääräinen paino $(\mathrm{g} / \mathrm{kpl})$.

6. Mekaaniset viat. Varastoinnin jälkeen perunoista arvosteltiin 50 mukulan näytteestä ruutua kohti mukuloittain 1) pintaviat (alle $2 \mathrm{~mm}: n$ hankautumat, $\varnothing$ yli $5 \mathrm{~mm}$ ), 2) maltoviat (yli $2 \mathrm{~mm}$ syvät haavat ja ruhjeet), 3) mustelmat (kuoren alaiset iskujen aiheuttamat maltoviat).

Tulosten tilastollisessa käsittelyssä käytettiin varianssianalyysejä, jotka laskettiin Keskusosuusliike Hankkijan ATK-osastolla. Tulosten tilastollinen merkitsevyys on ilmaistu tavanomaisia merkkejä käyttäen. 


\section{Tulokset}

Varianssianalyysien tulokset on esitetty Taulukossa 1.

Taulukko 1. Varsien poiston ja korjuuajan vaikutus Realta-perunan sadon määrään ja laatuun $(\mathrm{N}=72)$

Table 1. The effects of haulm cutting and harvest time on the yield and quality of Realta potatoes $(N=72)$

\begin{tabular}{|c|c|c|c|c|c|c|c|c|}
\hline \multirow[b]{2}{*}{$\begin{array}{l}\text { Tekijä } \\
\text { Factor }\end{array}$} & \multirow{2}{*}{ 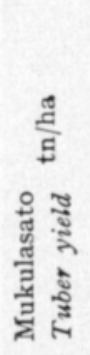 } & \multirow{2}{*}{ 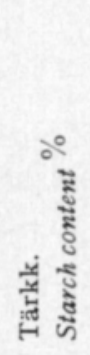 } & \multirow{2}{*}{ 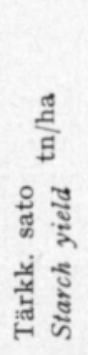 } & \multirow{2}{*}{ 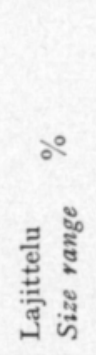 } & \multirow[b]{2}{*}{ 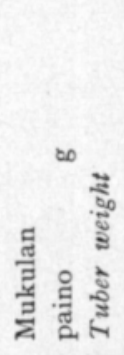 } & \multicolumn{3}{|c|}{$\begin{array}{l}\text { Mekaanisia vikoja } \\
\text { kpl/100 muk. } \\
\text { Mechanical damage } \\
\text { per } 100 \text { tubers }\end{array}$} \\
\hline & & & & & & 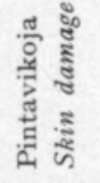 & 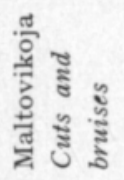 & 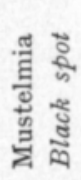 \\
\hline $\begin{array}{l}\text { A. Vuosi - Year } \\
\text { B. Varsien poisto }\end{array}$ & $* * *$ & $* *$ & $\cdots$ & $* * *$ & $\cdots$ & $* * *$ & $* * *$ & $* * *$ \\
\hline $\begin{array}{l}\text { Haulms cut ....... } \\
\text { c. Nostoaika - }\end{array}$ & $* * *$ & ns & $* *$ & $* *$ & $* \bullet$ & • & $(\bullet)$ & ns \\
\hline Harvest time ... & ns & ns & ns & ns & ns & • & $\cdot$ & $(*)$ \\
\hline AB & $(*)$ & $* * *$ & • & $* *$ & ns & • & ns & ns \\
\hline AC & $*$ & ns & $* * *$ & $* * *$ & ns & $*$ & ns & $(*)$ \\
\hline BC & ns & ns & ns & ns & $(*)$ & $(*)$ & ns & $(*)$ \\
\hline $\mathrm{ABC}$ & ns & ns & ns & ns & ns & ns & ns & $* *$ \\
\hline
\end{tabular}

\section{Mukulasato}

Mukulasadoissa oli vuotuista vaihtelua (A). Varsien poisto 20.08. alensi mukulasatoa keskim. $11 \%$ (B, Taulukot 1 ja 2).

Taulukko 2. Varsien poiston ja nostoajan vaikutus mukulasatoon.

Table 2. The effects of haulm cutting and harvest time on tuber yield.

\begin{tabular}{|c|c|c|c|}
\hline $\begin{array}{l}\text { Nostoaika } \\
\text { Harvest time }\end{array}$ & $\begin{array}{l}\text { Mukulasato } \\
\text { Poistettu } \\
\text { Haulms cut }\end{array}$ & $\begin{array}{c}\text { /ha }- \text { Tuber } \\
\text { Ei poistettu } \\
\text { Not cut }\end{array}$ & $\begin{array}{l}\text { ns/ha } \\
\text { Keskim. } \\
\text { Mean }\end{array}$ \\
\hline 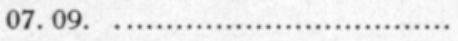 & 21.78 & 24.03 & 22.90 \\
\hline 16.09. & 21.50 & 24.88 & 23.19 \\
\hline 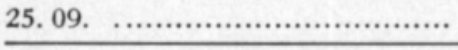 & 22.28 & 25.06 & 23.67 \\
\hline Keskim. - Mean .................... & 21.85 & 24.65 & \\
\hline PME - LSD $(5 \%)$ & $\begin{array}{l}\text { rsien poisto } 1.06 \\
\text { ulms cut }\end{array}$ & & \\
\hline
\end{tabular}


Sadon alennus oli jokavuotinen ilmiö, vaihdellen $1.90-4.20 \mathrm{tn} / \mathrm{ha}$, (vrt. RANTANEN 1969). Nostoaika ei keskimäärin vaikuttanut sadon määrään (C), mutta eri vuosina tulos oli vaihteleva (AC). V. 1969 Realta oli syyskuun alussa jo puolittain tuleentunut ja sato laski myöhäisissä korjuissa. V. 1970 sato ei muuttunut korjuuajan siirtyessä. V. 1971 taas mukulasato nousi 3.08 tn/ha ensimmäisen ja kolmannen noston välillä.

\section{Tärkkelyspitoisuus}

Sadon tärkkelyspitoisuus vaihteli vuosittain (A). Varsien poisto vaikutti tärkkelyspitoisuuteen vaihtelevasti eri vuosina, mutta keskimäärin vaikutus ei ollut merkitsevä (B, AB, Taulukot 1 ja 3). V. 1969 varsien paikalleen jättäminen alensi tärkkelyspitoisuutta, v. 1970 tärkkelyspitoisuus nousi ja v. 1971 ero ei ollut merkitsevä.

Taulukko 3. Varsien poiston ja nostoajan vaikutus tärkkelyspitoisuuteen. Table 3. The effects of haulm cutting and harvest time on the starch content.

\begin{tabular}{|c|c|c|c|}
\hline $\begin{array}{l}\text { Nostoaika } \\
\text { Harvest time }\end{array}$ & $\begin{array}{l}\text { Poistettu } \\
\text { Haulms cut }\end{array}$ & $\begin{array}{l}\text { Ei poistettu } \\
\text { Not cut }\end{array}$ & $\begin{array}{l}\text { Keskim. } \\
\text { Mean }\end{array}$ \\
\hline 07. $09 . \quad$............................... & 16.9 & 17.1 & 17.0 \\
\hline 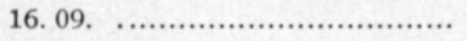 & 16.6 & 16.6 & 16.6 \\
\hline 25. 09. & 16.7 & 17.0 & 16.8 \\
\hline $\begin{array}{l}\text { Keskim. } \\
\text { Mean }\end{array}$ & 16.7 & 16.9 & \\
\hline
\end{tabular}

Nostoajan vaikutus tärkkelyspitoisuuteen ei myöskään ollut merkitsevä, vaikka suunta olikin lievästi aleneva nostoajan siirtyessä myöhäiseksi.

Tärkkelyssato

Tärkkelyssato vaihteli vuosittain (A). Varsien poisto alensi tärkkelyssatoa, tosin vuosittain vaihtelevassa määrässä (Taulukot 1 ja 4 ).

Taulukko 4. Varsien poiston ja nostoajan vaikutus tärkkelyssatoon (tn/ha).

Table 4. The effects of haulm cutting and harvest time on the starch yield (tons/ha).

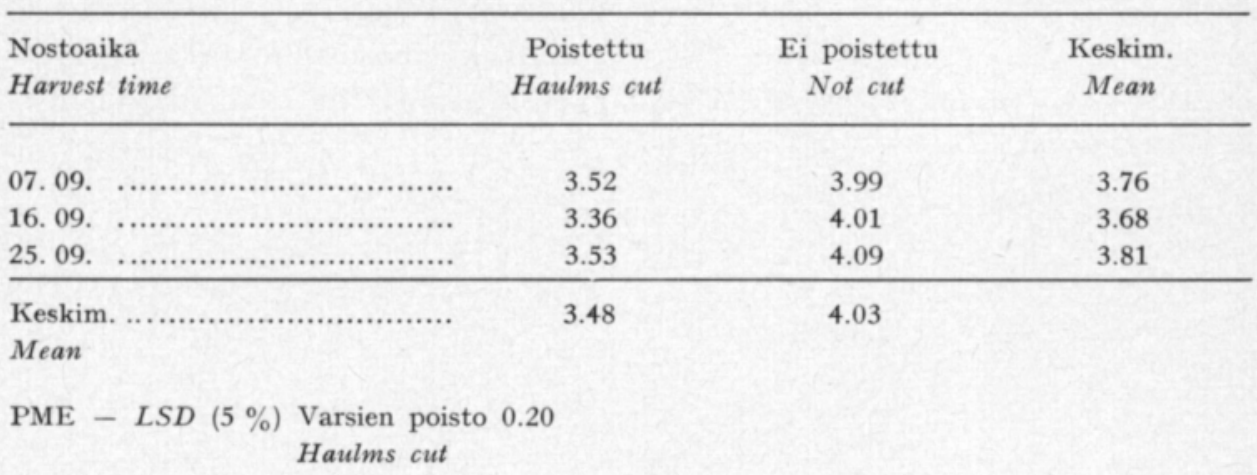


Nostoaika ei keskimäärin vaikuttanut tärkkelyssatoon, mutta vuotuiset vaihtelut olivat selvät (C, AC). V. 1969 tärkkelyssato aleni nostoajan siirtyessä, v. 1970 ei ollut selviä eroja, kun taas v. 1971 tärkkelyssadot nousivat nostoajan siirtyessä (vrt. mukulasadot).

\section{Mukuloiden koko}

Mukuloiden kokojakautuma vaihteli vuosittain (A) ja varsien poiston johdosta (B, Taulukot 1,5 ja 6).

Taulukot 5. Varsien poiston ja nostoajan vaikutus mukuloiden kokojakautumaan $(\%)$. Table 5. The effects of haulm cutting and harvest time on the size range of tubers (\%).

\begin{tabular}{|c|c|c|c|c|c|c|c|c|c|}
\hline \multirow[b]{2}{*}{$\begin{array}{l}\text { Nostoaika } \\
\text { Harvest time }\end{array}$} & \multicolumn{3}{|c|}{$\begin{array}{l}\text { Yli } 55 \mathrm{~mm} \\
\text { Over } 55 \mathrm{~mm}\end{array}$} & \multicolumn{3}{|c|}{$40-55 \mathrm{~mm}$} & \multicolumn{3}{|c|}{$\begin{array}{l}\text { Alle } 40 \mathrm{~mm} \\
\text { Under } 40 \mathrm{~mm}\end{array}$} \\
\hline & 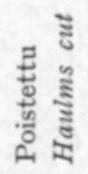 & 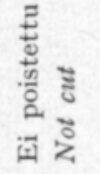 & 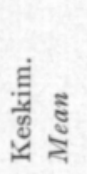 & 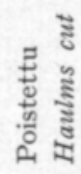 & 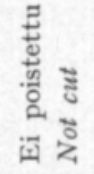 & 竎 & 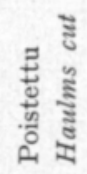 & 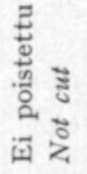 & 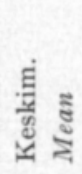 \\
\hline 07.09. ................... & 21 & 29 & 25 & 62 & 57 & 60 & 16 & 14 & 15 \\
\hline 16.09. & 23 & 31 & 27 & 60 & 56 & 58 & 17 & 13 & 15 \\
\hline 25.09. & 23 & 29 & 26 & 60 & 58 & 59 & 17 & 14 & 15 \\
\hline $\begin{array}{l}\text { Keskim. .................... } \\
\text { Mean }\end{array}$ & 22 & 29 & - & 61 & 57 & - & 17 & 14 & - \\
\hline
\end{tabular}

Varsien poistaminen vähensi selvästi isojen, mutta lisäsi keskikokoisten ja pienten mukuloiden osuutta. Rantanen (1969) totesi samoin suurten mukuloiden määrässä vähenemistä.

Nostoajan vaikutus kokojakautumaan oli merkityksetön (C), joskin kokojakautumassa oli vuotuista epäsäännöllistä vaihtelua (AC).

Varsien poistaminen aiheutti myös mukuloiden keskipainon merkitsevän alenemisen (B). Tämä painoero tasoittui kuitenkin nostoajan siirtyessä myöhäiseksi (AC, Taulukot 1 ja 6). Kokojakautumassa ei ollut samanlaista merkitsevää suuntaa. 
Taulukko 6. Varsien poiston ja nostoajan vaikutus mukulapainoon (g).

Table 6. The effects of haulm cutting and harvest time on the tuber weight $(\mathrm{g})$.

\begin{tabular}{lccc}
\hline $\begin{array}{l}\text { Nostoaika } \\
\text { Harvest time }\end{array}$ & $\begin{array}{c}\text { Poistettu } \\
\text { Haulms cut }\end{array}$ & $\begin{array}{c}\text { Ei poistettu } \\
\text { Not cut }\end{array}$ & $\begin{array}{c}\text { Keskim. } \\
\text { Mean }\end{array}$ \\
\hline & 70 & 92 & 81 \\
07.09. & 70 & 87 & 78 \\
16.09. & 78 & 78 & - \\
\hline Keskim. & 73 & & \\
Mean & & & \\
PME - LSD (5 \%) Varsien poisto 9 & & & \\
& Haulms cut & & \\
\end{tabular}

Perunoiden kolhiintuminen

Perunoiden vioittuminen nostossa ja lajittelussa vaihteli vuosittain (A). Varsien poistaminen vähensi pintavikoja muissa nostoissa paitsi ensimmäisessä (AB, Taulukko 1, Piirros 1). Maltovikojen lukumäärä väheni myös, mutta suunnilleen samalla tavalla kaikissa nostoissa (Piirros 2). Mustelmien määrään varsien poistaminen ei vaikuțtanut merkitsevästi. Ainoastaan viimeisessä nosțossa varsien poisto aiheuțti mustelmien märän lisääntymisen verrattuna kontrolliin (BC, Piirros 3).

Nostoaikojen välillä todetut erot eivät olleet johdonmukaisia: pintaviko-

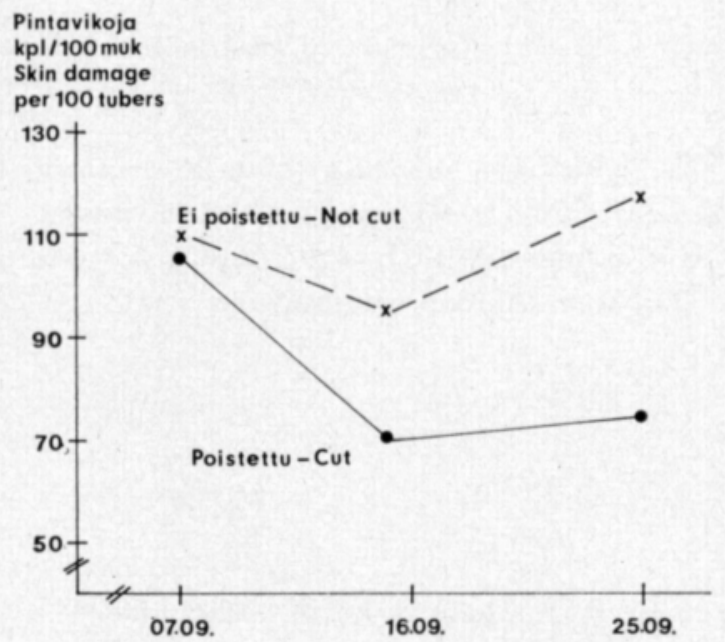

Piirros 1. Varsien poiston ja nostoajan vaikutus pintavikojen runsauteen.

Figure 1. The effects of haulm cutting and harvest time on the occurrence of skin damage. 


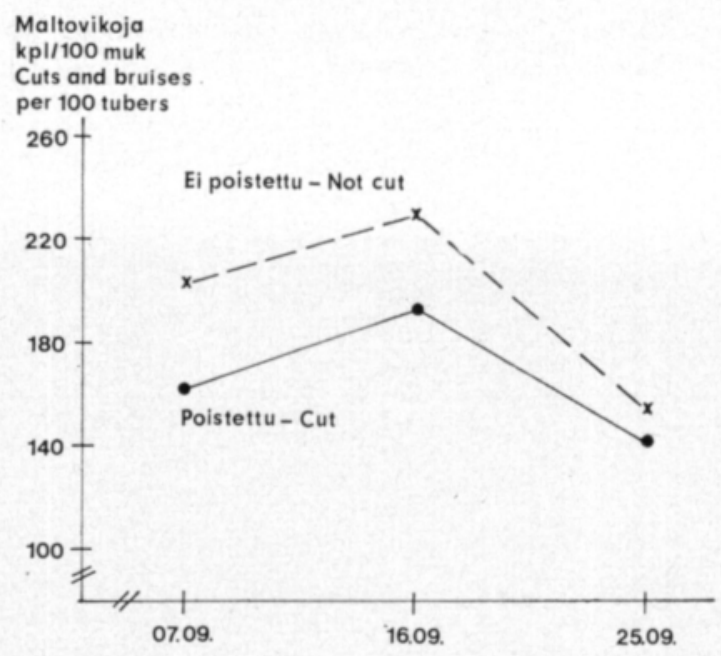

Piirros 2. Varsien poiston ja nostoajan vaikutus maltovikojen runsauteen.

Figure 2. The effects of haulm cutting and harvest time on the occurrence of cuts and bruises.

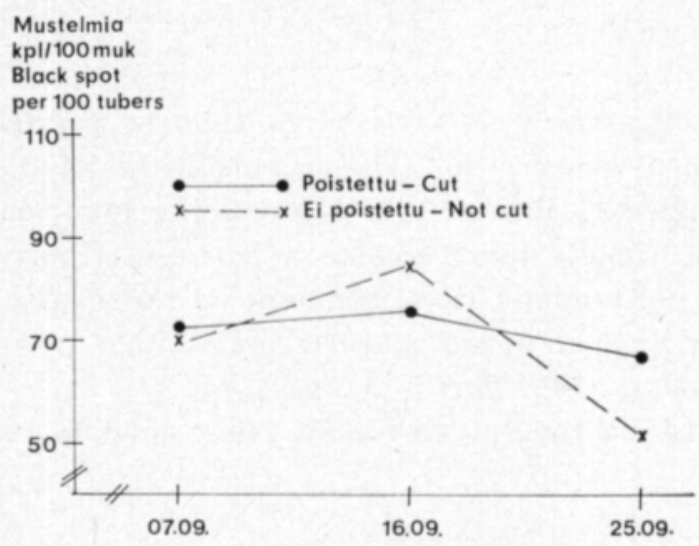

Piirros 3. Varsien poiston ja nostoajan vaikutus mustelmien runsauteen.

Figure 3. The effects of haulm cutting and harvest time on the occurrence of black spot.

jen määrä oli 2. ja 3. nostossa pienempi kuin 1. nostossa, kun taas muiden vikojen määrä oli suurin 2. nostossa ja pienin 3. nostossa. Syitä lienee haettava ulkoisten olosuhteiden vaihteluista. Vuotuista vaihtelua koejäsenten kesken todettiin kaikkien vikojen runsaudessa ( $\mathrm{AB}, \mathrm{AC}, \mathrm{ABC}$ ).

\section{Tulosten tarkastelua}

Sadon määrä

Varsien poiston ja korjuuajan vaikutus sadon määrään ja tärkkelyspitoisuuteen vaihtelee eri tapauksissa, kuten monet tutkimukset ovat osoittaneet (kirjallisuutta: VARIS 1970). Sadon määrä on tavallisesti suurimmillaan varsiston alkaessa tuleentua. Tästä lähtien assimilaatiotase muuttuu 
negatiiviseksi ja sadon määrä alkaa usein hitaasti laskea. Varsien katkaisemisen vaikutus satoon on siten riippuvainen kasvuston tuleentumisasteesta tai varsiston kunnosta. Varsien poiston jälkeenkin sadot saattavat muuttua eri tavalla riippuen esim. maan kosteudesta. Jos maa on ollut kuivaa ja varsien katkaisemisen jälkeen tulee sateita, saattavat mukulat ottaa vettä ja lisätä painoaan enemmän kuin varrellisessa kasvustossa, missä varsiston veden haihduttaminen poistaa osan vedestä. Tällaisessa tapauksessa tärkkelyspitoisuus laskee selvästi. Nämä muutokset ovat kuitenkin suhteellisen pieniä verrattuna satojen ja tärkkelyspitoisuuden yleisiin vuotuisiin vaihteluihin (vrt. VARIS 1970).

\section{Mekaaniset viat}

HEADFORDin (1963) tutkimuksissa, joissa sekä varsien tuhoamisaika että nostoaika vaihtelivat, todettiin varsien mekaanisen tai kemiallisen tuhoamisen vähentävän kuorivikoja samalla tavalla. Kuorivikoja oli sitä enemmän, mitä aikaisemmin varret tuhottiin ja perunat nostettiin ja mitä lyhyempi oli aika tuhoamisen ja noston välillä. Käsittelemättömissä kasvustoissa mukuloiden kuori vahvistui tuleentumisen edistyessä ja saavutti maksiminsa pian varsien kuivumisen jälkeen. Varsien tuhoaminen nopeutti kaikkina käsitțelykertoina kuoren vahvistumista. DАмвRотніn (1967) tutkimuksissa varsien poisțo 2 viikkoa ennen nostoa vähensi mekaanisia vikoja n. $20 \%$, mutta lajikkeiden välillä oli huomattavia eroja. Tuleentumisasteen edetessä kuorivikojen määrä väheni saavuttaen lopuksi lajikkeelle tyypillisen tason. Samalla kuitenkin mustelmien määrä lisääntyi. HAMPsonin ym. (1969) tutkimuksissa, joissa käytettiin kolmea varsien tuhoamiskertaa ja yhtä nostoaikaa, 4 viikon aika varsien tuhoamisesta korjuuseen vähensi huomattavasți mukuloiden vioittumista. Sen sijaan 2 viikon tai sitä lyhyempi aika ei tuottanut tulosta. Hunnius ja Fuchs (1970) totesivat puolestaan, että aikaisten ja melko aikaisten lajikkeiden vioittumisherkkyys lisääntyi korjuuajan siirryttyä täystuleentumisen ohi.

Ulkoisten olosuhteiden vaikutuksesta mekaanisten vikojen määrään mainittakoon tässä yhteydessä ne tutkimukset, joissa on selvitetty nostoajan lämpötilan ja maan kosteuden vaikutusta (SPECHT 1967, JoHNston ja WiLson 1969, PÄTzold 1969). Näiden tutkimusten mukaan perunoiden kuori- ja maltovikojen määrä lisääntyi lähes lineaarisesti lämpötilan alentuessa. Myös mustelmien määrässä todettiin sama suunta. Maan runsas kosteus vähensi kuorivikoja, mutta lisäsi mustelmia. Vuotuiset vaihtelut olivat kuitenkin suuret. Mainitut tutkijat pitävät korjuuajan lämpötilan vaikutusta tärkeimpänä tekijänä mekaanisten vikojen torjunnassa.

Selostettavassa tutkimuksessa oli varsien poiston osuus pintavikojen esiintymisessä suhteellisesti suurempi kuin nostoajan, mutta maltovikojen ja mustelmien suhteen tilanne oli päinvastainen. Nostoaikojen lämpötilojen ja mekaanisten vikojen runsauden välille ei tässä tutkimuksessa saatu korrelaatiota, joten erot johtuvat muista syistä. Varsien poiston ja maan jäähtymisen osittain vastakkainen vaikutus mekaanisten vikojen runsauteen näkyi tässä tutkimuksessa vain pintavikojen määrässä. 
Muiden ja tässä selostettujen tutkimustulosten perusteella voidaan perunan mukuloiden kolhiintumisherkkyyden muuttumisesta varsien poiston ja nostoajan funktiona päätellä seuraavaa:

- Kuorivikojen ja maltovikojen osuus vähenee, mustelmien määrä sen sijaan lisääntyy tuleentumisen edistyessä.

- Varsien joko mekaaninen tai kemiallinen tuhoaminen nopeuttaa kuoren vahvistumista ja vähentää kuori- ja maltovikoja. Varret on kuitenkin hävitettävä vähintäin 2 , mieluummin 3 viikkoa ennen korjuuaikaa.

- Varsien poistaminen vähentää jo aikaisessa nostossa maltovikoja. Myöhäisissä nostoissa myös kuoriviat vähenevät selvästi, maltovikojen määrä pysyy alhaisena, mutta mustelmien määrä saattaa lisääntyä.

- Maan ja perunoiden jäähtyminen lisää perunoiden vioittumisherkkyyttä. Varsien poistaminen näyttää Suomen olosuhteissa olevan hyödyllisintä aikaisia ja melko aikaisia lajikkeita viljeltäessä sekä siemenperunan tuotannossa. Perunat olisi kuitenkin tällöin nostettava syyskuun alkupuolella ja varret poistettava $2-3$ viikkoa ennen nostoa. Mikäli nosto siirtyy syyskuun lopulle, vähenee varsien poiston merkitys mekaanisten vikojen torjunnassa kuorivikoja lukuunottamatta.

\section{Yhteenveto}

Perunan varsien mekaanisen poiston ja nostoajan yhteisvaikutusta Realtaperunan sadon määrään ja laatuun tutkittiin Hankkijan kasvinjalostuslaitoksella vuosina 1969-71. Varret poistettiin 20. 08., nostoajat olivat 07. 09., 16. 09. ja 25. 09 .

Varsien poisto alensi mukulasatoa keskimäärin $11 \%$. Nostoajan merkitys ei ollut keskimäärin merkitsevä, vaikkakin vuotuisia eroja todettiin.

Varsien poiston ja nostoajan vaikutus tärkkelyspitoisuuteen oli merkityksettömän pieni. Vuotuiset erot olivat tosin selvät.

Varsien poisto alensi tärkkelyssatoa. Nostoajan vaikutus oli vuosittain vaihteleva, mutta keskimäärin merkityksetön.

Varsien poisto vähensi isojen ja lisäsi keskikokoisten ja pienten mukuloiden osuutta sadossa. Nostoajan vaikutus ei ollut merkitsevä.

Varsien poisto alensi mukuloiden keskipainoa. Ero tasaantui kuitenkin viimeisessä nostossa. Nostoaika ei vaikuttanut merkitsevästi.

Varsien poisto vähensi selvästi pintavikojen osuutta toisessa ja kolmannessa nostossa. Toisessa nostossa oli pintavikoja vähemmän kuin muissa.

Varsien poisto vähensi maltovikoja kaikissa nostoissa. Maltovikoja oli vähiten viimeisessä nostossa.

Varsien poisto ei vaikuttanut mustelmien määrään. Ainoastaan viimeisessä nostossa oli mustelmien määrässä lisääntyvä suunta. Mustelmia oli vähiten viimeisessä nostossa. 


\section{KIRJALLISUUTTA}

Dамвroth, M. 1967. Der Einfluss von Umwelt und pflanzenbaulichen Massnahmen auf die spezifische Widerstandsfähigkeit von Kartoffelknollen gegen mechanische Belastungen. Diss. 149 p. Giessen.

Fuchs, G. 1971. Untersuchungen zur Vollernteverträgligkeit der Kartoffel. Bayer. Landw. J. buch 48: $847-865$.

Glemmestad, E. 1957. Mekaniske skader på potetene ved opptakinga. Norsk Landbr. 19: 3-9.

Hampson, C. P., Dent, T. J. \& Fox, W. R. 1969. Investigations on damage and damage susceptibility measurements on potatoes. 4th Trienn. Conf. E. A. P. R.: 246.

HEADFORD, D. W. R. 1963. The effect of pre-harvest destruction or removal of the foliage on the skin-setting of potato tubers. 2nd Trienn. Conf. E. A. P. R.: 179.

HunniUs, W. \& Fuchs, G. 1970. Zur Prüfung der Vollernteverträglichkeit von Kartoffelsorten. Potato Res. 13: 305-322.

Johnston, E. F. \& WiLson, J. B. 1969. Effect of soil temperatures at harvest on the bruise resistance of potatoes. Amer. Potato J. 46: 75-82.

LAMPE, K. 1960. Die Widerstandsfähigkeit von Kartoffelknollen gegen Beschädigungen. Eur. Potato J. 3: $13-29$.

Lööw, H. 1964. Mekaniska skador på matpotatis. Jordbr.tekn. Inst. Medd. 304: 1-49.

Nylund, R. E., Hemphill, P., Lutz, J. M. \& Sorenson, H. 1955. Mechanical damage to potatoes during harvesting and handling operations in the Red River Valley of Minnesota and North Dakota. Amer. Potato J. 32: 237-247.

Pärzold, C. 1969. Beschädigungsempfindlichkeit von Kartoffelknollen in Abhängigkeit von klimatischen Faktoren. 4nd Trienn. Conf. E. A. P. R.: 241.

RANtANen, T. 1969. Perunanvarsiston hävittäminen. Koetoim. ja Käyt. 26: 3.

- - \& Varis, E. 1969. Peruna. Koetoim. ja Käyt. 26: 30-31.

SEPPÄNEN, E. 1972 a. On the external quality of table potatoes in Finland and factors influencing it. Ann. Agric. Fenn. 11: 119-134.

$-1972 \mathrm{~b}$. The resistance of ten potato varieties to mechanical injury. J. Scien. Agric. Soc. Finl. 44: 93-97.

SPECHT, A. 1967. Schaffung optimaler Rodebedingungen für den Kartoffelsammelroder. Versuchsstation Dethlingen. Versuchsberich 1967: 30-40.

VARIS, E. 1970. Variation in the quality of table potato and the factors influencing it in Finland. Acta Agr. Fenn. 118,3: 1-99. 